\title{
Comparison of maturation and physical performance in basketball athletes of different playing positions
}

\section{Comparação da maturação e desempenho físico em atletas de basquetebol de diferentes posições de jogo}

\author{
Lilian Keila Barazetti ${ }^{1}$ \\ (1) https://orcid. ora/0000-0002-5694-9835 \\ Pedro Rafael Varoni \\ (D) https://orcid org/0000-0001-7768-5405 \\ Fernando de Souza Campos ${ }^{2}$ \\ (D) https://orcid.org/0000-0001-9937-1538 \\ Michelli Demarchi \\ (D) https://orcid.org/0000-0002-3121-2271 \\ Lucielle Baumann \\ (D) https://orcid.org/0000-0002-0142-8258 \\ Anderson Santiago Teixeira ${ }^{2}$ \\ (D) https://orcid.org/0000-0001-7508-9917 \\ Renan Felipe Hartmann Nunes ${ }^{2,3}$ \\ (iD) https://orcidorg/0000-0003-4153-7747 \\ Lucinar Jupir Forner Flores ${ }^{1}$ \\ (iD) https://orcid.org/0000-0002-4010-7596
}

Abstract - The aim of this study was to compare the characteristics of somatic maturation, anthropometric and physical performance (vertical jump and aerobic power) in young basketball players of different playing positions (under 13 years) and analyze these relationships using Peak Height Velocity (PHV) as a measure of somatic maturation. For this, 26 male athletes were evaluated. Anthropometric variables were: body mass, standing and sitting height, and length of lower limbs. Maturation was determined by age at PHV. Physical performance was determined by lower limb power (counter movement jump - CMJ) and aerobic power (Intermittent Recovery Test) tests. MANOVA reported significant differences $(p<0.05)$ among playing positions regarding variables Maturity Offset, estimated PHV age, standing height, sitting height, estimated leg length, body mass and Yo-Yo IR1. In addition, it was identified that point guards reached estimated PHV at later age than their peers who act as small forwards and centers. Regarding CMJ, no significant differences were identified among playing positions, but in relation to aerobic power, point guards and small forwards presented higher performance. These findings confirm that maturation has great effect on growth and physical performance measures and the estimated PHV age is an applicable tool in young athletes, mainly aiding professionals in structuring the teaching-learning- training process in this age group. Key words: Anthropometry; Athletic performance; Basketball; Sexual maturation.

Resumo - O objetivo do presente estudo foi comparar as características de maturação somática, antropométricas e desempenho físico entre as posiçôes de jogo em jogadores de Basquetebol sub-13 e analisar estas relaçóes utilizando o Pico de Velocidade de Crescimento (PVC) como uma medida da maturação somática. Para tanto, 26 atletas do sexo masculino foram avaliados. As variáveis antropométricas foram: massa corporal, estatura em pé e sentado e comprimento de membros inferiores. A maturação foi determinada pela idade do PVC. O desempenho físico foi através dos testes de potência de membros inferiores (salto com contra movimento - CMJ) e potência aeróbia (Yo-Yo IR1). A MANOVA reportou diferenças significativas $(p<0,05)$ entre as posiçöes em quadra nas variáveis Maturity Offset, idade do PVC estimado, estatura, altura sentado, comprimento de pernas estimado (CPE), massa corporal e Yo-Yo IR1. Além disso, foi identificado que os armadores alcançaram o PVC estimado, em uma idade mais tarde que seus companheiros que atuam como alas e pivôs. Em relação ao CMJ não foram identificadas diferenças significativas entre as posiçôes, já em relação a potência aeróbia, os armadores e alas apresentaram desempenho significativo superior quando comparados aos pivôs. Estes achados confirmam que a maturaçẫo tem um grande efeito nas medidas de crescimento e desempenho físico e a determinação da idade estimada do PVC apresenta-se como uma ferramenta aplicável em jovens atletas, principalmente no auxílio de profissionais na estruturação do processo de ensino-aprendizagem-treinamento nesta faixa etária.

Palavras-chave: Antropometria; Basquetebol; Desempenho atlético; Maturidade sexual.
1 State University of Western Paraná. Marechal Candido Rondon, PR. Brazil.

2 Federal University of Santa Catarina. Florianópolis, SC. Brazil

3 Department of Physiology. Clube Atlético Tubarão. Tubarão, SC. Brazil

Received: November 16, 2018 Accepted: July 22, 2019

How to cite this article Barazetti LK, Varoni PR, Campos FS, Demarchi M, Baumann L, Teixeira AS, Nunes R, Flores LJF.Comparison of maturation and physical performance in different playing positions basketball athletes. Rev Bras Cineantropom Desempenho Hum 2019, 21:e60248. DOl: http://dx.doi.org/10.1590/19800037.2019v21e60248

Copyright: This work is licensed under a Creative Commons Attribution 4.0 International License. 


\section{INTRODUCTION}

Basketball has become one of the most popular sports worldwide, especially among young adolescents ${ }^{1}$. It is characterized as a high-intensity modality with short recovery periods, requiring aerobic power and muscle power, especially of lower limbs ${ }^{1,2}$. During matches, although movements occur in small spaces, different tasks and actions such as sprints, jumps, accelerations, decelerations, and constant changes of direction are required from athletes ${ }^{3-5}$. However, these characteristics may be influenced by the maturity of these individuals, since physical performance is directly related to maturational stage, body size and years of training in young athletes ${ }^{6}$.

Maturation consists of structural and functional body changes during development to maturity ${ }^{6}$. Thus, in order to identify athletes during the maturational process, a non-invasive instrument was proposed, which is easy to access and possible to be used in cross-sectional studies, predicting the distance (in years) that the individual is from peak height velocity $(\mathrm{PHV})^{7}$. Some studies have shown that male athletes reach PHV at 14 years of age ${ }^{8,9}$; however, there is maturity time variation among individuals ${ }^{10}$, which consequently can be reflected in the different playing positions in Basketball ${ }^{11}$.

Previous studies have shown that the game demands are related to the tactical, physical and anthropometric elements in basketball athletes ${ }^{12}$. For example, Pehar et al. ${ }^{5}$ demonstrated that point guards have lower body mass and height indexes than centers, as well as better aerobic performance ${ }^{4}$ and vertical jump height ${ }^{13}$ when compared to their peers (small forwards and centers). However, there is no consensus in literature whether these differences demonstrate the same behavior after using estimated PHV age to control the effect of somatic maturation of different positions on young basketball athletes.

In this context, there seems to be a tendency for smaller basketball athletes, such as point guards, to reach the estimated PHV at later age, while centers reach it at an earlier age, i.e., with earlier maturation process ${ }^{14,15}$. These differences indicate that the playing position may be influenced by maturational aspects, but few studies have analyzed this behavior in the U-13 category ${ }^{8,9}$, age in which athletes approach PHV. In this sense, understanding these relationships during this process becomes relevant to professionals in the area, especially in helping them to prescribe training effectively and individually. Therefore, the primary aim of the present study was to compare the somatic maturation, anthropometric and physical performance (vertical jump and aerobic power) characteristics among playing positions and to analyze these relationships using PHV as a measure of the degree of somatic maturation interdependence in young basketball players (U-13).

\section{METHOD}

\section{Participants}

The sample consisted of 26 male basketball athletes divided into three 
playing positions; small forwards $(n=12)$, point guards $(n=6)$ and centers $(\mathrm{n}=8)$ belonging to the Parana U-13 team (Table 1). Data collection was performed during preparation to the National Championship, and in this phase, athletes trained between four and five times a week, with sessions lasting between 60 and 90 minutes in the afternoon, in addition to friendly matches. Specifically, athletes engaged in technical and tactical activities such as reduced games, activities with numerical superiority and inferiority, collective training, coordinative exercises, and conditioning skills were developed during these activities. In addition, the sample can be classified as elite athletes for participating in State and National competitions.

Parents or guardians of athletes received clarifications regarding the study purpose, collection procedures, benefits and possible risks of their children's participation in the present study. Subsequently, they were submitted to voluntary participation by signing the informed consent form, signed by parents, according to guidelines proposed by Resolution 466/12 of the National Health Council on research involving human beings, approved by the Ethics Research Committee of the State University of Western Paraná under CAAE number: 01334812.5.0000.0107.

\section{Experimental design}

Athletes participating in this study represented their clubs / schools in municipal, regional and state competitions; specifically during the first semester of 2017. After the end of this period, athletes were summoned by the Paraná basketball federation to compose the state team in the Brazilian championship of the respective category. Athletes participated in a 3 -week training period prior to the national competition. Finally, before training, anthropometric and physical evaluations were performed to obtain individual information.

Participants underwent two data collection sessions, held at the local gym, scheduled on different days according to schedules agreed with the technical committee, with minimum interval of 24 and maximum interval of 48 hours. In the first session, anthropometric evaluation was conducted, followed by familiarization with the aerobic and lower limb power tests. In the second session, in the morning, countermovement jump Test (CMJ) was performed and in the afternoon, the Intermittent Recovery Test (YoYo IR1). All participants were instructed not to exercise the day before, as well as not to eat high-energy foods and / or caffeine-containing drinks for a period prior to three hours before tests. Evaluations were performed in the morning between 09:00 am and 11:00 am and in afternoon between 02:00 pm and 05:00 pm, with temperature variation between 23 and $25^{\circ} \mathrm{C}$.

\section{Collection Instruments}

Anthropometric variables were composed of body mass, standing and sitting height and lower limb length. Body mass (Toledo, model 2096, Brazil) and height (Sanny, Standard model, Brazil) were obtained according to procedures proposed by Alvarez and Pavan ${ }^{16}$. For trunk-cephalic 
height, lower limb length was measured from the difference between trunk-cephalic height and individual's height. Body mass index (BMI) was determined using the following formula: $\mathrm{BMI}=$ weight $(\mathrm{kg}) /(\text { height })^{2}(\mathrm{~m})$.

$\mathrm{PHV}$ assessment was based on the proposal by Koziel and Malina ${ }^{17}$, which could predict the distance in years that an individual is from the PHV age. The model was included of age and height interactions. From these data, the Maturity Offset formula for boys in years was used: -7.9999994 + $(0.0036124 \mathrm{x}$ (age $\mathrm{x}$ height). The authors report that this new equation has reduced variation compared to original equations, being useful for assessing maturity more accurately, and PHV has higher consistency in biological classification, being considered an ideal measure to group subjects within a common maturation marker.

To assess lower limb power, CMJ height was used through a contact mat (Jump System Pro, Cefise, Brazil). Prior to performing the jumping protocol, lower limb joint warm-up was performed, followed by 5 submaximal jumps, respecting 5 minutes of rest until testing. Each participant performed three maximal random CMJs with a 20-second interval between each jump. To perform the jump, the athlete stood on the mat with hands fixed to the hip and at the signal of the evaluator, the athlete performed a squat, followed by a jump. Athletes were encouraged to perform as much effort as possible. The best result among jumps was recorded ${ }^{18}$.

The Yo-Yo IR1 test was used to evaluate the aerobic power of athletes. It consisted of 2 shuttle run tests in a 20 -meter cone-demarcated space, interspersed with 10 seconds of active recovery (controlled by "beep" signal performed by an amplified speaker) using a 5-meter space marked with cones. The Yo-Yo IR1 test started with 4 shuttle run tests between 10 and $13 \mathrm{~km} \cdot \mathrm{h}^{-1}(0-160 \mathrm{~m})$ followed by 7 shuttle run tests between 13.5 and $14 \mathrm{~km} \cdot \mathrm{h}^{-1}(160-440 \mathrm{~m})$, following an increase of $0.5 \mathrm{~km} \cdot \mathrm{h}^{-1}$ every 8 runs. Athletes were familiarized with test before starting, and warm-up was also performed. Athletes were evaluated simultaneously and were verbally encouraged to perform as much effort as possible. The test was completed when the athlete reached voluntary exhaustion ${ }^{19}$.

\section{Statistical analysis}

To verify data normality, the Shapiro-Wilk test was used. Levene's test was used to test homoscedasticity, while data sphericity was verified by the Mauchly's test. When the last assumption was violated, the GreenhouseGeisser correction was adopted. Due to the parametric non-violation, central tendency (mean) and dispersion (standard deviation) measures were used to describe the investigation variables. Effect size (Cohen's) was used to investigate differences in maturity and estimated $\mathrm{PHV}$ age for each and among playing positions. The effect size (ES) was defined according to Cohen's ${ }^{20}$ classification: <0.2: trivial; 0.2-0.5: small; 0.5-0.8: moderate; > 0.8: large. Multivariate analysis of variance (MANOVA) was performed to determine differences in chronological age, $\mathrm{PHV}$ age, anthropometric characteristics and performance among playing positions. In addition, 
multivariate analysis of covariance (MANCOVA) with chronological age and $\mathrm{PHV}$ age was used as dependent covariate for comparison of anthropometric and performance characteristics. Statistical procedures were performed using the Statistical Package for Social Sciences (SPSS, version 19.0) for Windows. The significance level adopted was $\mathrm{p}<0.05$.

\section{RESULTS}

Comparison of anthropometric variables, estimated $\mathrm{PHV}$ age and lower limb aerobic power among playing positions are presented in table 1 . MANOVA reported significant difference among playing positions in variables Maturity Offset, estimated PHV age, height, sitting height, estimated leg length (ELL) ( $\mathrm{p}<0.001)$, body mass and Yo-Yo IR1 ( $<0.05)$. No difference was found among playing positions in variables chronological age, BMI and CMJ ( $p>0.05$ ). In addition, ES presented moderate and large values in the following anthropometric variables: Maturity Offset, estimated PHV age, body mass, height, sitting height, ELL and BMI, especially centers in relation to the other positions. Moreover, variables $\mathrm{CMJ}$ and Yo-Yo IR1 presented moderate and large ES, and in the aerobic power test, centers reported shorter distance traveled compared to small forwards and point guards (ES = 1.05 and 1.16).

Table 2 presents the MANCOVA values using the estimated PHV age as covariate. After controlling differences with estimated PHV age among positions, variable ELL showed significant difference $(p<0.05)$, and lower values were found for small forwards when compared to point guards $(\mathrm{ES}=$ moderate $)$ and centers $(\mathrm{ES}=$ large $)$. Similarly, significant differences were reported for the distance traveled (Yo-Yo IR1; $\mathrm{p}<0.05$ ), and these values were lower for centers when compared to small forwards and point guards ( $\mathrm{ES}=$ large).

Table 1. Descriptive statistics (mean \pm SD) of age, somatic maturation, anthropometric characteristics and physical performance among playing positions, and MANOVA results with effect size (with $90 \% \mathrm{Cl}$ ).

\begin{tabular}{|c|c|c|c|c|c|c|c|c|}
\hline \multirow[b]{2}{*}{ Variables } & \multicolumn{3}{|c|}{ Mean \pm SD } & \multicolumn{2}{|c|}{ MANOVA } & \multicolumn{3}{|c|}{ Effect Sizes (Cohen's d) } \\
\hline & $\begin{array}{l}\text { Small forwards [1] } \\
\qquad(n=12)\end{array}$ & $\begin{array}{l}\text { Point guards [2] } \\
\qquad(n=6)\end{array}$ & $\begin{array}{l}\text { Centers [3] } \\
\quad(n=8)\end{array}$ & $\mathrm{F}$ & $p$-value & 1 vs. 2 & 1 vs. 3 & 2 vs. 3 \\
\hline Chronological age (years) & $13.13 \pm 0.24$ & $13.22 \pm 0.30$ & $13.30 \pm 0.24$ & 1.102 & 0.349 & $-0,21$ & $-0,53$ & $-0,25$ \\
\hline Maturity Offset (years) & $0.27 \pm 0.34$ & $-0.27 \pm 0.46$ & $0.77 \pm 0.37$ & 13.174 & 0.000 & 1,06 & $-1,10$ & $-2,49$ \\
\hline Estimated PHV age (years) & $12.85 \pm 0.33$ & $13.51 \pm 0.28$ & $12.53 \pm 0.19$ & 20.113 & 0.000 & $-2,00$ & 1,45 & 4,53 \\
\hline Body mass (kg) & $65.27 \pm 9.07$ & $49.58 \pm 3.60$ & $71.41 \pm 14.72$ & 7.858 & 0.003 & 3,67 & $-0,37$ & $-1,32$ \\
\hline Height (cm) & $174.42 \pm 6.70$ & $161.50 \pm 7.06$ & $182.50 \pm 5.07$ & 18.877 & 0.000 & 1,60 & $-1,33$ & $-3,68$ \\
\hline Sitting Height (cm) & $109.08 \pm 3.70$ & $100.41 \pm 3.77$ & $111.00 \pm 4.84$ & 12.757 & 0.000 & 1,99 & $-0,30$ & $-1,94$ \\
\hline ELL (cm) & $65.30 \pm 3.96$ & $61.08 \pm 5.14$ & $71.50 \pm 2.07$ & 13.423 & 0.000 & 0,73 & $-2,55$ & $-4,47$ \\
\hline $\mathrm{BMI}\left(\mathrm{kg} / \mathrm{m}^{2}\right)$ & $21.47 \pm 2.84$ & $19.03 \pm 1.22$ & $21.37 \pm 3.98$ & 1.478 & 0.249 & 1,67 & 0,02 & $-0,52$ \\
\hline CMJ (cm) & $31.00 \pm 4.66$ & $29.01 \pm 2.70$ & $29.85 \pm 4.06$ & 0.500 & 0.613 & 0,63 & 0,26 & $-0,18$ \\
\hline Yo-YolR1(m) & $926.67 \pm 196.76$ & $953.33 \pm 186.61$ & $640.00 \pm 240.00$ & 5.579 & 0.011 & $-0,14$ & 1,05 & 1,16 \\
\hline
\end{tabular}

Note ELL: estimated leg length; BMI: body mass index; PHV: peak height velocity. SD: standard deviation; MANOVA: Multivariate analysis of variance. 
Table 2. Descriptive statistics (mean \pm SE) of age, anthropometric characteristics and physical performance among playing positions, and MANCOVA results using the estimated PHV age as covariate, with Effect Size (with $90 \% \mathrm{CI}$ ).

\begin{tabular}{|c|c|c|c|c|c|c|c|c|}
\hline \multirow{2}{*}{ Variables } & \multicolumn{3}{|c|}{ Mean \pm SD } & \multicolumn{2}{|c|}{ MANCOVA } & \multicolumn{3}{|c|}{ EffectSizes (Cohen's d) } \\
\hline & $\begin{array}{l}\text { Small forwards [1] } \\
\qquad(\mathrm{n}=12)\end{array}$ & $\begin{array}{l}\text { Point guards [2] } \\
\qquad(\mathrm{n}=6)\end{array}$ & $\begin{array}{l}\text { Centers [3] } \\
\qquad(n=8)\end{array}$ & $\mathrm{F}$ & $p$-value & 1 vs. 2 & 1 vs. 3 & 2 vs. 3 \\
\hline Chronological age (years) & $13.13 \pm 0.24$ & $13.22 \pm 0.30$ & $13.30 \pm 0.24$ & 1.102 & 0.349 & -0.10 & $-0,23$ & $-0,11$ \\
\hline Body mass (kg) & $64.65 \pm 2.91$ & $56.94 \pm 5.98$ & $66.82 \pm 4.46$ & 0.682 & 0.516 & 0.44 & $-0,15$ & $-0,70$ \\
\hline Height (cm) & $174.42 \pm 6.70$ & $161.50 \pm 7.06$ & $182.50 \pm 5.07$ & 0.860 & 0.437 & 0.63 & $-0,50$ & $-1,30$ \\
\hline Sitting Height (cm) & $108.55 \pm 0.82$ & $106.72 \pm 1.69$ & $107.07 \pm 1.26$ & 1.036 & 0.372 & 0.37 & 0,37 & $-0,09$ \\
\hline ELL (cm) & $64.78 \pm 0.70$ & $67.32 \pm 1.45$ & $67.60 \pm 1.08$ & 4.012 & 0.033 & -0.60 & $-0,82$ & $-0,08$ \\
\hline BMI $\left(\mathrm{kg} / \mathrm{m}^{2}\right)$ & $21.52 \pm 0.89$ & $18.44 \pm 1.82$ & $21.74 \pm 1.36$ & 1.073 & 0.359 & 0.58 & $-0,05$ & $-0,76$ \\
\hline CMJ (cm) & $30.98 \pm 1.22$ & $29.18 \pm 2.52$ & $29.75 \pm 1.88$ & 0.386 & 0.684 & 0.25 & 0,21 & $-0,10$ \\
\hline Yo-YolR1(m) & $927.31 \pm 62.13$ & $945.61 \pm 127.55$ & $644.80 \pm 95.22$ & 3.325 & 0.055 & -0.05 & 0,93 & 0,99 \\
\hline
\end{tabular}

Note ELL: estimated leg length; BMI: body mass index; PHV: peak height velocity. SD: standard deviation; MANCOVA: multivariate analysis of covariance.

\section{DISCUSSION}

The main findings of this study showed that there are significant variations among playing positions for somatic maturation measures, anthropometric variables and physical performance in young Brazilian basketball players. However, after using estimated PHV age as covariate to control the effect of somatic maturation, differences related to playing position were found only for estimated leg length and distance traveled in the Yo-Yo IR1 test. These findings suggest that inter-individual variations related to the growth and biological maturation process directly interfere with the decision making of coaches and other professionals involved in the selection process of young talents, especially regarding the definition and specialization of playing positions.

In general, the results of this study showed that point guards achieved estimated $\mathrm{PHV}$ at later age $(13.51 \pm 0.28$ years) compared to small forwards $(12.85 \pm 0.33$ years $)$ and centers $(12.53 \pm 0.19$ years). Due to this slower / late biological maturation rate, point guards are lighter, shorter, have lower sitting height and estimated leg length values than small forwards and centers.

In a previous study with 43 young Dutch basketball players, Wierike et al. ${ }^{10}$ also showed that point guards $(13.73 \pm 0.40$ years $)$ reached PHV at a later age compared to small forwards (12.78 \pm 0.68 years) and centers (12.67 \pm 0.76 years). These results are in agreement with the findings of other studies that reported that biological maturation and anthropometric characteristics have influenced the process of specialization of playing positions in basketball ${ }^{21}$ and other collective modalities ${ }^{22}$. Interestingly, these position-specific anthropometric characteristics identified in adolescents are similar to those observed in adult players ${ }^{22}$. This denotes that coaches are relying especially on the characteristics of players from adult professional teams to select and train their adolescent athletes, who are still undergoing the growth and biological maturation process, in certain playing positions.

However, it is noteworthy that maturation-related differences tend to 
disappear in late adolescence ${ }^{23,24}$, and that late-maturing athletes at the end of their biological maturation process can reach or even surpass their normal or early-maturing peers regarding anthropometric or physical performance characteristics ${ }^{24,25}$. Thus, coaches and other professionals responsible for structuring the teaching-learning-training process in young players of similar age to the present study (13 years) should stimulate the development of technical-tactical skills in a holistic way for the different playing positions, avoiding restricting the athletes' development to a single tactical function due to their momentary anthropometric characteristic, which is directly influenced by the level of biological maturation.

In the present study, no significant differences were reported among playing positions for vertical jump performance. On the other hand, significant differences related to playing position were found for intermittent aerobic power assessed by the total distance traveled in the Yo-Yo IR1 test. Although differences among playing positions for intermittent aerobic power were reduced after controlling for the influence of somatic maturation (estimated PHV age), point guards and small forwarders continued to outperform in the Yo-Yo IR1 test compared to centers, as demonstrated by the large ES (0.93 and 0.99, Table 2), respectively. Although it may seem inconsistent for less mature players (small forwarders and point guards) to outperform Yo-Yo IR1 in relation to more mature players (centers), it is likely that metabolic and neuromuscular changes that occur with maturation may be used as a justification to explain these results. Studies available in literature have shown that metabolic and neuromuscular changes that occur with the biological maturation process maximize the development of anaerobic metabolism and adversely influence energy production through aerobic metabolism ${ }^{26,27}$. For example, Doncaster et al. ${ }^{28}$ have shown that soccer players of the same chronological age classified as pre-PHV (less mature) have higher "efficiency" in using the oxidative system for energy production (represented by faster oxygen uptake kinetics) compared to players who were near or beyond PHV (more mature). In addition, better running economy at submaximal intensities has been observed in late or normal maturing players compared to their "early" maturation peers ${ }^{28,29}$. These combined characteristics, indicating better use of the aerobic pathway and greater movement efficiency at submaximal intensities, may partially explain the better performance found in the Yo-Yo IR1 test of slower biological maturation players such as point guards.

Regarding aspects related to early specialization, especially related to playing positions, studies have shown that athletes should preferably start to specialize in a position from the age of $16^{29}$. Wierike et al. ${ }^{10}$ investigated whether young basketball athletes have changed positions over two consecutive seasons and concluded that most of them specialize in a specific position and remain in it throughout their development. Thus, athletes younger than 16 years of age should train more versatile with respect to playing position, and younger athletes should participate in more sports in order to develop fundamental motor skills ${ }^{10}$. 
The limitations of this study were based on some situations, such as the use of mathematical formula to estimate the predicted $\mathrm{PHV}$ age, whereas the ideal would be the wrist radiography method (gold standard). The reduced number of subjects, as athletes are of different teams and consequently are submitted to different training models, as well as the impossibility of controlling intervening variables (food, sleep, among others), are other limitations.

\section{CONCLUSION}

The results of the present study demonstrate variations for somatic maturation, anthropometric variables and physical performance among playing positions in young basketball athletes. However, these differences are minimized when comparisons are controlled through estimated PHV age, as reported from ES values. These findings confirm that maturation has a significant effect on growth and physical performance measures, and these differences among playing positions may be due to maturity time variability.

In this sense, determining the estimated PHV age is an applicable tool in young athletes, especially to help professionals in structuring the teaching-learning-training process in this age group. Finally, further studies should explore maturational changes among playing positions over the seasons, taking into account the control of training loads, performance of physical and anthropometric capacities.

\section{COMPLIANCE WITH ETHICAL STANDARDS}

\section{Funding}

This research received financial support through scientific initiation scholarships (PV; MD), masters scholarships (LB; FC) and doctorate (RN) from Conselho Nacional de Desenvolvimento Científico e Tecnológico (CNPq), Fundação Araucária and Coordenação de Aperfeiçoamento de Pessoal de Nível Superior (CAPES).

\section{Ethical approval}

Ethical approval was obtained from the local Human Research Ethics Committee - State University of Western Parana and protocol (CAAE: 01334812.5.0000.0107) was written in accordance with standards set by the Declaration of Helsinki.

\section{Conflict of interest statement}

The authors have no conflict of interests to declare.

\section{Author Contributions}

Conceived and designed the experiments: LKB; LF. Performed the experiments: LKB; PV; FC; MD. Analyzed data: FC; AT; RN. Contributed with reagents/materials/analysis tools: LKB; PV; MD. Wrote the paper: LKB; FC; LB; AT; RN; LF. 


\section{REFERENCES}

1. Latzel R, Hoos O, Stier S, Kaufmann S, Fresz V, Reim D, et al. Energetic profile of the basketball exercise simulation test in junior elite players. Int J Sports Physiol Perform 2018;13(6):810-815.

2. Aoki MS, Ronda LT, Marcelino PR, Drago G, Carling C, Bradley PS, et al. Monitoring training loads in professional basketball players engaged in a periodized training program. J Strength Cond Res 2017;31(2):348-358.

3. Gantois P, Aidar FJ, Dantas M, Silva LM, Paes PP, Santana EE, et al. Aerobic fitness is associated with improved repeated sprints ability of basketball players after six weeks of training during preseason. Rev Bras Cineantropom Desempenho Hum 2018;20(1):114-124.

4. Ben Abdelkrim N, Castagna C, Jabri I, Battikh T, El Fazaa S, Ati J El. Activity profile and physiological requirements of junior elite basketball players in relation to aerobic-anaerobic fitness. J Strength Cond Res 2010;24(9):2330-2342.

5. Pehar M, Sekulic D, Sisic N, Spasic M, Uljevic O, Krolo A, et al. Evaluation of different jumping tests in defining position-specific and performance-level differences in high level basketball players. Biol Sport 2017;3(3):263-272.

6. Malina RM, Eisenmann JC, Cumming SP, Ribeiro B, Aroso J. Maturity-associated variation in the growth and functional capacities of youth football (soccer) players 13-15 years. Eur J Appl Physiol 2004;91(5-6):555-562.

7. Mirwald RL, Baxter-Jones AD, Bailey DA, Beunen GP. An assessment of maturity from anthropometric measurements. MedSci Sport Exerc 2002;34(4):689-694.

8. Carvalho HM, Coelho-e-Silva MJ, Gonçalves CE, Philippaerts RM, Castagna C, Malina RM. Age-related variation of anaerobic power after controlling for size and maturation in adolescent basketball players. Ann Hum Biol 2011;38(6):721-727.

9. Beunen G, Malina RM. Growth and biologic maturation: relevance to athletic performance. In: Hebestreit $\mathrm{H}$; Bar-Or O, organizadores. The young athlete. Oxford, UK: Blackwell Publishing Ltd; 2007. p. 3-17.

10. te Wierike SC, Elferink-Gemser MT, Tromp EJ, Vaeyens R, Visscher C. Role of maturity timing in selection procedures and in the specialization of playing positions in youth basketball. J Sports Sci 2015;33(4):337-345.

11. Ziv G, Lidor R. Physical attributes, physiological characteristics, on-court performances and nutritional strategies of female and male basketball players. Sports Med 2009;39(7):547-568.

12. Chen WH, Wu HJ, Lo SL, Chen H, Yang WW, Huang CF, et al. Eight-week battle rope training improves multiple physical fitness dimensions and shooting accuracy in collegiate basketball players. J Strength Cond Res 2018;32(10):2715-2724.

13. Boone J, Bourgois J. Morphological and physiological profile of elite basketball players in belgium. Int J Sports Physiol Perform 2013;8(6):630-638.

14. Hoare DG. Predicting success in junior elite basketball players--the contribution of anthropometric and physiological attributes. J Sci Med Sport 2000;3(4):391-405.

15. Ostojic SM, Mazic S, Dikic N. Profiling in basketball: physical and physiological characteristics of elite players. J StrengthCond Res 2006;20(4):740-744.

16. Alvarez BR, Pavan AL. Alturas e comprimentos. In: Petroski EL, organizador. Antropometria: técnicas e padronizações. $2^{\mathrm{a}}$ ed. Porto Alegre: Palotti; 2003. p. 31-47.

17. Kozieł SM, Malina RM. Modified maturity offset prediction equations: validation in independent longitudinal samples of boys and girls. Sports Med 2018;48(1):221-236.

18. Bosco C. Strength Assessment with the Bosco's Test. Italian Society of Sport Science; 1999.

19. Krustrup P, Mohr M, Amstrup T, Rysgaard T, Johansen J, Steensberg A, et al. The yo-yo intermittent recovery test: physiological response, reliability, and validity. Med Sci Sports Exerc 2003;35(4):697-705.

20. Cohen, J. Statistical power analysis for the behavioral sciences. No. 300.72 C6. 1988. 
21. Köklü Y, Alemdaroğlu U, Koçak FU, Erol AE, Fındıkoğlu G. Comparison of chosen physical fitness characteristics of turkish professional basketball players by division and playing position. J Hum Kinet 2011;30(1):99-106.

22. Matthys SPJ, Fransen J, Vaeyens R, Lenoir M, Philippaerts R. Differences in biological maturation, anthropometry and physical performance between playing positions in youth team handball. J Sports Sci 2013;31(12):1344-1352.

23. Meylan C, Cronin J, Oliver J, Hughes M. Talent identification in soccer: the role of maturity status on physical, physiological and technical characteristics. Int J Sports Sci Coach 2010;5(4):571-592.

24. Pearson DT, Naughton GA, Torode M. Predictability of physiological testing and the role of maturation in talent identification for adolescent team sports. J Sci Med Sport 2006;9(4):277-287.

25. Beunen GP, Malina RM, Lefevre J, Claessens AL, Renson R, Simons J. Prediction of adult stature and noninvasive assessment of biological maturation. Med Sci Sports Exerc 1997;29(2):225-230.

26. Armstrong N, Barker AR, McManus AM. Muscle metabolism changes with age and maturation: How do they relate to youth sport performance? Br J Sports Med 2015;49(13):860-864.

27. Birat A, Bourdier P, Piponnier E, Blazevich AJ, Maciejewski H, Duché P, et al. Metabolic and fatigue profiles are comparable between prepubertal children and well-trained adult endurance athletes. Front Physiol 2018 Apr 24;9:387.

28. Doncaster G, Iga J, Unnithan V. Assessing differences in cardiorespiratory fitness with respect to maturity status in highly trained youth soccer players. Pediatr Exerc Sci 2018;30(2):216-228.

29. Teixeira AS, Guglielmo LGA, Fernandes-da-Silva J, Konarski JM, Costa D, Duarte JP, et al. Skeletal maturity and oxygen uptake in youth soccer controlling for concurrent size descriptors. Plos One 2018;13(10):e0205976.

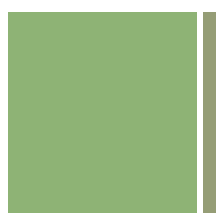

Corresponding author

Lucinar J. Forner Flores

State University of Western Parana- Unioeste-

Marechal C. Rondon-PR, Brazil.

Rua Pernambuco, 1777- Marechal C. Rondon-PR Brazil ZIP Postal 85 960-000

Email: lucinar.flores@unioeste.br 